\title{
Chemical characterisation of potential pheromones from the shoulder gland of the Northern yellow-shouldered-bat, Sturnira parvidens (Phyllostomidae: Stenodermatinae)
}

\author{
Chris G Faulkes ${ }^{\text {Corresp., } 1}$, J. Stephen Elmore ${ }^{2}$, David A Baines ${ }^{3}$, Brock Fenton ${ }^{4}$, Nancy B Simmons ${ }^{5}$, Elizabeth L. \\ Clare \\ ${ }^{1}$ School of Biological \& Chemical Sciences, Queen Mary University of London, London, United Kingdom \\ 2 Department of Food and Nutritional Sciences, University of Reading, Reading, United Kingdom \\ 3 Baines Food Consultancy Ltd, Thornbury, Bristol, United Kingdom \\ 4 Department of Biology, University of Western Ontario, Ontario, Canada \\ 5 Department of Mammalogy Division of Vertebrate Zoology, American Museum of Natural History, New York, United States of America \\ Corresponding Author: Chris G Faulkes \\ Email address: c.g.faulkes@qmul.ac.uk
}

Bats of the genus Sturnira (Family Phyllostomidae) are characterised by shoulder glands that are more developed in reproductively mature adult males. The glands produce a waxy secretion that accumulates on the fur around the gland, dyeing the fur a dark colour and giving off a pungent odour. These shoulder glands are thought to play a role in their reproductive behaviour. Using gas chromatography-mass spectrometry, we analysed solvent extracts of fur surrounding the shoulder gland in the northern-shouldered bat,Sturnira parvidensto (i) characterise the chemical composition of shoulder gland secretions for the first time, and (ii) look for differences in chemical composition among and between adult males, sub-adult/juvenile males and adult females. Fur solvent extracts were analysed as liquids and also further extracted using headspace solid-phase microextraction to identify volatile components in the odour itself.Odour fingerprint analysis using non-metric multidimensional scaling (NMDS) plots and multivariate analysis revealed clear and significant differences $(P<0.001)$ between adult males versus both juvenile males and adult females. The chemical components of the shoulder gland secretion included terpenes and phenolics, together with alcohols and esters, most likely derived from the frugivorous diet of the bat. Many of the compounds identified were found exclusively or in elevated quantities among adult (reproductive) males compared with adult females and non-reproductive (juvenile) males. This strongly suggests a specific role in male-female attraction although a function in male-male competition and/or species recognition is also possible. 
1 Chemical characterisation of potential pheromones from the shoulder gland of the Northern 2 yellow-shouldered-bat, Sturnira parvidens (Phyllostomidae: Stenodermatinae)

3 Chris G. Faulkes ${ }^{1}$, J. Stephen Elmore ${ }^{2}$, David A. Baines ${ }^{3}$, Brock Fenton ${ }^{4}$, Nancy B. Simmons ${ }^{5}$,

4 Elizabeth L. Clare ${ }^{1}$

$6{ }^{1}$ School of Biological \& Chemical Sciences, Queen Mary University of London, London, United 7 Kingdom

$9 \quad{ }^{2}$ Department of Food and Nutritional Sciences, University of Reading, Reading, United

10 Kingdom

11

${ }^{3}$ Baines Food Consultancy Ltd, Thornbury, Bristol, United Kingdom

${ }^{4}$ Department of Biology, University of Western Ontario, Ontario, Canada

${ }^{5}$ Department of Mammalogy, Division of Vertebrate Zoology, American Museum of Natural History, New York, United States of America

Corresponding Author:

Chris G. Faulkes ${ }^{1}$

c.g.faulkes@qmul.ac.uk 


\section{Abstract}

28 Bats of the genus Sturnira (Family Phyllostomidae) are characterised by shoulder glands that are more developed in reproductively mature adult males. The glands produce a waxy secretion that accumulates on the fur around the gland, dyeing the fur a dark colour and giving off a pungent odour. These shoulder glands are thought to play a role in their reproductive behaviour. Using gas chromatography-mass spectrometry, we analysed solvent extracts of fur surrounding the

33 shoulder gland in the northern-shouldered bat, Sturnira parvidens to (i) characterise the chemical 34 composition of shoulder gland secretions for the first time, and (ii) look for differences in 35 chemical composition among and between adult males, sub-adult/juvenile males and adult females. Fur solvent extracts were analysed as liquids and also further extracted using headspace solid-phase microextraction to identify volatile components in the odour itself. Odour fingerprint analysis using non-metric multidimensional scaling (NMDS) plots and multivariate analysis revealed clear and significant differences $(\mathrm{P}<0.001)$ between adult males versus both juvenile males and adult females. The chemical components of the shoulder gland secretion included

41 terpenes and phenolics, together with alcohols and esters, most likely derived from the

42 frugivorous diet of the bat. Many of the compounds identified were found exclusively or in 43 elevated quantities among adult (reproductive) males compared with adult females and non-

44 reproductive (juvenile) males. This strongly suggests a specific role in male-female attraction 45 although a function in male-male competition and/or species recognition is also possible. 


\section{Introduction}

48 Pheromones are intra-specific semiochemicals (chemical signals) that modify the behaviour

49 and/or physiology in the recipient animal. They occur across the animal kingdom and are

50 particularly well characterised in insects. Among mammals, there are many examples of

51 pheromonal communication (see Wyatt, 2014 for recent review), but their chemical composition

52 and actions in mammals has been debated (Doty, 2010). There are two general categories of

53 semiochemicals within a species: pheromones, chemical signals which elicit a stereotypical

54 behavioural or physiological response in the recipient animal, while signature mixtures are odour

55 cues which are learned by the conspecific receivers and often have complex and variable

chemical profiles. These "individual mixtures" or "signature odours", which act in social

communication though learning may identify a specific individual or social group (Wyatt 2014,

2017; Dehnhard 2011).

Bats (order Chiroptera), are the second most speciose mammalian order (after Rodentia), yet relatively little is known about the possible role of pheromonal communication in this group.

Bats exhibit a wide variety of social and mating systems, implying the need for individual recognition within groups, and exchange of social and reproductive cues (including mate choice). A nocturnal lifestyle and potentially limited visual cues, particularly in roosts, could exaggerate the importance of auditory and olfactory cues. Chemical cues are known to be used by big brown bats Eptesicus fuscus (Bloss et al., 2002), and implicated in Bechstein's bats, Myotis bechsteinii (Safi \& Kirth, 2003) and the fisherman bat, Noctilio leporinus (Brooke \& Decker, 1996). While the exquisitely complex auditory systems associated with echolocation in bats have been studied for years, work on their olfactory systems is more limited. Both the primary and secondary olfactory systems are involved in pheromonal chemoreception, with the latter 
70 forming the vomeronasal organ (VNO). A comparative anatomical study by Wible and

71 Bhatnagar (1996) looked across more than a hundred genera of bats and found extensive

72 variation in the presence or absence of the VNO, implying convergent gains and losses of the

73 structure. More recently, genomic studies have investigated the genes coding for olfactory

74 receptor proteins. Young et al. (2010) reported that two bat species (the little brown bat, Myotis

75 lucifugus, and the flying fox, Pteropus vampyrus) completely lacked intact genes for functional

76 receptors (V1R) in the VNO and they identified only inactive pseudogenes. Furthermore,

77 inactivating mutations in the vomeronasal signal transduction gene Trpc 2 were also

78 characterised, suggesting that any VNO or secondary olfactory epithelia (if present) would be non-responsive to pheromonal signals. Yohe et al. (2017) used Trpc2 as a molecular marker for

80 examining evolutionary losses and gains of the VNO system in more than 100 species across 17

81 of the 21 extant bat families. They found that all bats examined exhibit degraded vomeronasal

82 systems, except for some members of Miniopteridae and Phyllostomidae. The Sturnira lilium

83 species complex, which includes our study species Sturnira parvidens, does have a VNO and

84 does not have a pseudogenisation in $\operatorname{Trpc} 2$ exon 2, which would prevent signal transduction

85 (Yohe et al. 2017), suggesting a functional VNO and a potential role for pheromonal signalling

86 in this group. Collectively, these anatomical and genetic studies indicate that some, but not all,

87 bat species have the anatomical and physiological substrates required in the accessory olfactory

88 system for potentially receiving and responding to pheromones. However, pheromones in

89 mammals are also detected by the main olfactory system (Wyatt 2014, 2017) so the lack of

90 functioning VNO receptors does not rule out the possibility of semiochemical signaling.

91 Evidence for olfaction acting as a sensory modality for individual discrimination in bats

92 has also been gathered from behavioural studies. Scent-choice experiments by Bouchard (2001) 
93 demonstrated that two African molossid bats (Mops condylurus and Chaerephon pumilus) can

94 distinguish between the sexes and distinguish roost-mates from strangers using olfactory cues. A

95 number of species in the family Emballonuridae have sacs in their wing or tail membranes,

96 which may function in a scent-based identification social system. These sacs are typically larger

97 and better developed in adult males. In the best-studied example by Voigt and von Helversen

98 (1999), male Saccopteryx bilineata keep harems of females and use their paired wing sacs

99 (located near the forward edge of each wing) to store bodily fluids. These fluids are then sprayed

100 on females during hovering or used in characteristic "salting" behaviour. Females also possess

101 wing sacs but they are rudimentary and the same behaviours have not been observed (Voigt \&

102 von Helversen, 1999).

103 Despite observations that imply important roles for olfaction in social behaviour of bats,

104 there are few papers that identify the chemical make-up of chiropteran pheromones. Bloss et al.

105 (2002) found that female big brown bats, Eptesicus fuscus (Family Vespertilionidae) use

106 chemical cues to distinguish among female conspecifics, and these authors potentially identified

10714 compounds based on analysis of their retention index on the gas chromatograph. Similarly,

108 Caspers et al. (2008) and later Schneeberger et al. (2016) established that the odour

109 "fingerprints" presented to females by male Saccopteryx bilineata contained differences

110 associated with age, colony, and year of sample collection. Thus, these signals could provide

111 information to females for assessing potential male mates. However, Schneeberger et al. (2016)

112 did not report the actual chemical composition of the wing-sac liquids. Other species of bats have

113 different structures that seem to produce odoriferous secretions possibly used in social

114 communication. Many species of molossids as well as the phyllostomid Trachops cirrhosis have

115 a single gland in the ventral midline of the throat which is found either exclusively in males or is 
116 best developed in adult males (Bowles et al., 1990; Scully et al., 2000; Tandler et al., 1999;

117 Phillips et al., 1987). Male Noctilio leporhinus (Family Noctioionidae) secrete a strongly

118 smelling sticky substance along their lateral fur (N. Simmons, personal observation, 2017). The

119 chemical composition of these secretions has never been investigated.

120 The shoulder glands of Sturnira species are well known but understudied. Sturnira are

121 widely distributed and abundant from north-western Mexico, through Central America and into

122 tropical and subtropical South America (to the north of Argentina and Uruguay) and the Lesser

123 Antilles (Gannon et al., 1989; Velazco \& Patterson, 2013; 2014). The common name of this

124 genus (yellow-shouldered bats) refers to glandular scent organs on the shoulder that produce a

125 yellowish or reddish staining of the fur that surrounds them (Figure 1). These glands are most

126 highly developed in males, and development of these glands appears to be dependent on the

127 reproductive maturity of the individual (Scully et al. 2000). In mature males they are described

128 as emitting a "strong, sweetish, musky odour" (Gannon et al., 1989; Goodwin \& Greenhall,

129 1961) that can be so strong it is detectable by humans several metres away (E Clare, unpublished

130 observation).

131 Histological examination of the shoulder glandular region of male Sturnira revealed

132 numerous hair follicles and associated sebaceous glands, with scattered small sudoriferous

133 glands in a deeper layer of adipose tissue. The same glandular elements were also present in

134 females, although the size of the glandular region varied between males and females. Females

135 lack both the strong odour and strongly coloured hairs stained from secretion (Scully et al.,

136 2000). The production of a strongly-smelling secretion in reproductively mature males implies a

137 potential pheromonal role for these odours in reproduction, although very little has been reported 
138 about the social or mating system of these species, and no behavioural or chemical analysis has

139 been done.

140 Our goal was to chemically characterise, for the first time, the secretions from the

141 shoulder gland of the northern yellow-shouldered bat, Sturnira parvidens. Using a gas

142 chromatography-mass spectrometry (GC-MS) approach, we identify the constituents and

143 compare the odour profiles among adult males, juvenile (non-reproductive) males, and adult

144 females.

145

146 Methods

147 Sample collection and storage

148 We conducted field work and collected samples in 2015 and 2016 at sites in Orange Walk

149 District, Belize, including the Lamanai Archaeological Reserve and adjacent secondary forest

150 and gardens near the Lamanai Outpost Lodge $(17.75117 \mathrm{~N},-88.65446 \mathrm{~W})$, and a forest fragment

151 at the Ka'kabish Archaeological Project (17.8147 N, 148 -88.73052 W) Our research was

152 conducted in accordance with accepted standards for humane capture and handling of bats

153 published by the American Society of Mammalogists (Sikes et al. 2016) and approved

154 Institutional Animal Care and Use Committee protocols (Brown University IACUC 1205016 and

155 1504000134). Locally, the fieldwork was carried out with Belize Forestry Department Scientific

156 Research and Collecting Permits CD/60/3/15 (20) and WL/1/1/16 (26) respectively. All samples

157 were collected during a 10-day field trip at the end of April and the start of May to control for

158 any potential seasonal variation. We captured bats using mist nets set along forest paths, and

159 each individual was briefly contained in a cloth "bat bag" for identification and processing. We

160 determined sex and then checked for age and reproductive maturity in males by examining the 
161 genitalia and ossification of the wing joints, following methods described by Racey (1988) and

162 Anthony (1988): males were classified as reproductive based on the size and descent of testes

163 into the scrotal sac, and as an adult if wing joints were ossified. We removed a small sample of

164 fur of the same size (approximately $4 \mathrm{~mm}^{2}$ ) from an equivalent area surrounding the shoulder

165 gland on all individuals, using sterile scissors. More specifically, fur was collected from a

166 discoloured patch where oil was being secreted in adult males (Figure 1), while for adult females

167 and juveniles we collected fur from the same physical location as the adult males (which is often

168 also slightly discoloured). After fur was collected, we released all bats at the site of their capture.

169 Each fur sample was stored in a $2 \mathrm{ml}$ screw-topped Eppendorf tube containing $1 \mathrm{~mL}$ of glyceryl

170 trioctanoate (Sigma-Aldrich, Gillingham, Dorset, UK), a medium-chain triglyceride (MCT), at

171 ambient temperature for later chemical analysis (within 2 months). The MCT acts as a solvent,

172 stabilizing and dissolving the organic components of any secretions from the shoulder gland.

174 Direct injection of MCT extracts

175 MCT extracts were analysed by gas chromatography-mass spectrometry (GC-MS), using an

176 Agilent 7693 autoinjector and Agilent 6890N gas chromatograph with 5975 mass spectrometer

177 (Agilent, Santa Clara, CA). The GC column used was a $15 \mathrm{~m} \times 0.25 \mathrm{~mm}$ HP-5MS UI column

$178\left(0.25 \mu \mathrm{m}\right.$ film thickness; Agilent) and injection was in split mode $(10: 1)$ at $250{ }^{\circ} \mathrm{C}$, the injection

179 volume being $1 \mu \mathrm{L}$. The initial temperature of the $\mathrm{GC}$ oven was $100{ }^{\circ} \mathrm{C}(0 \mathrm{~min})$, rising at $5{ }^{\circ} \mathrm{C}$

180 per min to $320^{\circ} \mathrm{C}$. Helium was used as the carrier gas at a constant flow rate of $1.1 \mathrm{~mL} / \mathrm{min}$. A

181 series of $n$-alkanes $\left(C_{5}-C_{30}\right)$ in diethyl ether were analysed, under the same conditions, to obtain

182 linear retention index (LRI) values for the components of the extract. 
$184 \mathrm{eV}$, scanning from $\mathrm{m} / \mathrm{z} 29$ to $\mathrm{m} / \mathrm{z} 800$ at 1.9 scans/s. We identified compounds by first comparing

185 their mass spectra with those contained in the NIST/EPA/NIH Mass Spectral Database or in

186 previously published literature. Wherever possible identities of compounds were confirmed by

187 comparison of linear retention index (LRI) values, with either those of authentic standards or

188 published values.

191 Headspace solid-phase microextraction

192 We carried out volatile compound analysis by automated headspace solid-phase microextraction

193 (SPME), followed by GC-MS, using an Agilent 110 PAL injection system and Agilent 7890 gas

194 chromatograph with 5975C mass spectrometer. The SPME fibre stationary phase was composed 195 of $75 \mu \mathrm{m}$ divinylbenzene/Carboxen ${ }^{\mathrm{TM}}$ on polydimethylsiloxane (Supelco, Bellefonte, PA). The 196 uncapped 2-mL vials containing the MCT extracts were placed in 20-mL headspace vials. The

197 samples were then equilibrated for 10 minutes at $37^{\circ} \mathrm{C}$ before being extracted for $30 \mathrm{~min}$.

198 Samples were agitated at $500 \mathrm{rpm}$ ( $5 \mathrm{~s}$ on, $2 \mathrm{~s}$ off) during equilibration and extraction. After 199 extraction, the contents of the fibre were desorbed in splitless mode at $250{ }^{\circ} \mathrm{C}$ onto the front of a 200 Stabilwax DA fused silica capillary column (30 m, $0.25 \mathrm{~mm}$ i.d., $0.50 \mu \mathrm{m}$ film thickness; Restek,

201 Bellefonte PA). The GC temperature program and the fibre desorption step commenced at the 202 same time. During the desorption period of $45 \mathrm{~s}$, the oven was held at $40{ }^{\circ} \mathrm{C}$. After desorption, 203 the oven was held at $40^{\circ} \mathrm{C}$ for a further $255 \mathrm{~s}$ before heating at $4{ }^{\circ} \mathrm{C} / \mathrm{min}$ to $260{ }^{\circ} \mathrm{C}$, where the 204 temperature was maintained for $5 \mathrm{~min}$. Helium was used as the carrier gas at a constant flow rate 205 of $0.9 \mathrm{~mL} / \mathrm{min}$. A series of $n$-alkanes $\left(\mathrm{C}_{5}-\mathrm{C}_{22}\right)$ in diethyl ether was analysed, under the same 
206 conditions, to obtain LRI values for the components of the extract. To check for the presence of

207 volatiles contributed from the MCT solvent, we ran a blank extraction of the MCT alone within

208 the sample vial. We detected some octanoic acid (this was predicted, as the MCT used was

209 glyceryl trioctanoate), that we note in the results.

210 The mass spectrometer operated in electron impact mode with an electron energy of 70

$211 \mathrm{eV}$, scanning from $\mathrm{m} / \mathrm{z} 20$ to $\mathrm{m} / \mathrm{z} 280$ at 1.9 scans/s. As with the direct injection protocol, we

212 identified compounds by first comparing their mass spectra with those contained in the

213 NIST/EPA/NIH Mass Spectral Database or in previously published literature. Wherever possible

214 we then confirmed identities by comparison of linear retention index (LRI) values with those of

215 authentic standards.

216

\section{Chemical confirmation of compounds identified}

218 Authentic standards for confirmation of identities and/or synthesis included 3,4-

219 dimethoxybenzoic acid (veratric acid) (I), 4-(4-methoxyphenyl)butyric acid (II), $\beta$-(4-hydroxy-3-

220 methoxyphenyl)propionic acid (III), 3-(3,4-dimethoxyphenyl)propionic acid (IV), linalool oxide

221 (pyranoid), 3,4-dimethylbenzaldehyde, 1-methoxy-2-propanol, 1-propanol and acrylic acid, all

222 purchased from Tokyo Chemical Industry UK, Ltd (Oxford, UK); 3-(3,5-dimethoxy-4-

223 hydroxyphenyl)propionic acid (V) was purchased from Carbosynth (Compton, UK); $\beta$-(3-

224 hydroxy-4-methoxyphenyl)propionic acid (VI), anthranilic acid (VII), vanillic acid (VIII),

225 octanoic acid (IX), salicylic acid (X) and propylene glycol were obtained from Sigma-Aldrich

226 (Gillingham, Dorset, UK).

227 To confirm the identities of tentatively identified propyl and hydroxypropyl esters, we

228 performed synthesis using acids I to $\mathrm{X}$ above. Ten reactions were carried out in 1-mL Reacti- 
229 Vials (Thermo Fisher Scientific). Each Reacti-Vial contained $0.2 \mathrm{~g}$ of acid and $0.2-0.6 \mathrm{~mL}$ of a

230 1:1 mixture of 1-propanol and propylene glycol plus 1 drop of hydrochloric acid as catalyst. The

231 amount of alcohol added depended on the solubility of the acid. Reaction mixtures were heated

232 for $30 \mathrm{~min}$ at $80^{\circ} \mathrm{C}$ and then neutralised by dropwise addition of $0.1 \mathrm{M}$ sodium bicarbonate. The

233 esters were then transferred to $7-\mathrm{mL}$ glass bottles and $2 \mathrm{~mL}$ of diethyl ether were added. The

234 contents of the bottles were then stirred at $700 \mathrm{rpm}$ using a magnetic stirrer for 5 minutes. The

235 contents were allowed to settle and the ether layer was removed for analysis by GC-MS, after

236 addition of a small amount of anhydrous sodium sulfate to remove any water still present. The

237 GC-MS conditions used were the same as those used for the direct injection of the MCT

238 extracts, only with a split ratio of 100:1.

239

240 Statistical analysis

241 We identified GC peaks and calculated their retention index and peak areas using the software

242 MSD Chemstation E02.02.1431 (2011; Agilent, Santa Clara, CA). For direct injection and

243 headspace analyses, we compared both mean peak areas from the GC output and the relative

244 peak area (\%) of each compound to the total peak area (of all peaks we identified) among adult

245 males (of reproductive age), subadult/juvenile males (non-reproductive), and adult females.

246 Absolute mean peak areas give an indication of quantitative differences between samples and

247 groups but can be subject to variance in sampling. The percentage peak areas normalise the data

248 across samples, and correct for differences in absolute amounts of starting sample (due to the

249 difficulties in taking an equivalent amount of fur and secretion from each bat). In our analyses,

250 we examined both mean and relative (\%) peak areas. Taking an approach used by Schneeberger

251 et al. (2016), we compared the overall chemical compositions (the "odour fingerprint") of each 
252 individual sample. A Bray-Curtis dissimilarity index was then computed using adult males,

253 juvenile males and adult females as categories for prediction in a non-parametric analysis of

254 similarities (ANOSIM) and to identify significant differences among groups. We visualised data

255 in two dimensions with a non-metric multidimensional scaling (NMDS) ordination. Similarity

256 percentage (SIMPER) was then used to identify significant differences between equivalent peaks

257 in each sample, and, hence, which odour components contributed most to the differences

258 between groups. We performed all analyses using the VEGAN package in RStudio (version

259 1.0.136), and both the ANOSIM and SIMPER procedures used 1000 permutations.

260

\section{Results}

262 We identified 15 compounds in medium-chain triglyceride extracts of fur surrounding the

263 shoulder gland of Sturnira parvidens, some of which differed significantly between adult males

264 and juvenile males/adult females ( $\mathrm{n}=5$ samples from each age/sex class; Table 1; Supplementary

265 Figure 1). Three of the 15 compounds occurred only in adult males, namely vanillic acid, 3,4-

266 dimethoxybenzoic acid (veratric acid), and 3-(3,4-dimethoxyphenyl)propionic acid. We found

267 two other compounds in both adult males and females (levels significantly higher in males), but

268 not juvenile males: hydroisoferulic acid propyl ester and 3-(3,5-dimethoxy-4-

269 hydroxyphenyl)propionic acid propyl ester. Four additional compounds showed significant

270 differences between the three groups, and in all cases the adult males had higher levels of these

271 compounds, while juvenile males did not differ from females. Of these four, $\alpha, \beta$-dihydroferulic

272 acid propyl ester had the greatest peak area; the other compounds were the propyl ester of

273 anthranilic acid, 4-(4-methoxyphenyl)butyric acid, the propyl ester of $\alpha, \beta$-dihydroferulic acid,

274 and the hydroxypropyl ester of $\alpha, \beta$-dihydroferulic acid. A single compound, $\beta$-(4-hydroxy-3- 
275 methoxyphenyl)propionic acid ( $\alpha, \beta$-dihydroferulic acid), was found in all groups and while

276 higher in adult males, only reached a significant difference in adult males versus adult females.

277 Supplementary Table 1 provides supporting mass spectral data of the fifteen compounds

278 identified in the medium-chain triglyceride extracts of fur.

279 We undertook headspace concentration of the solvent extract, to discover if there were

280 compounds of interest present at low concentrations in the fur extract. Table 2 lists the headspace

281 compounds in medium-chain triglyceride extracts of fur surrounding the shoulder gland of

282 Sturnira parvidens, obtained using solid-phase microextraction, and representative

283 chromatograms are shown in Supplementary Figure 2. These are the more volatile components in

284 the extracted glandular secretion from Sturnira parvidens shoulder gland fur. We identified 42

285 compounds, 33 showing significant differences between adult males, juvenile males and adult

286 females for peak area (6 compounds), percentage peak area (14 compounds) or both (13

287 compounds). Twenty-one peaks were higher and eleven peaks were lower in adult males,

288 compared to females and juveniles. One peak was higher in females versus juvenile males for

289 percentage peak area (acrylic acid). Collectively these results indicate that adult male shoulder

290 gland secretion odour profiles are distinct from those of females and juvenile males. The twelve

291 peaks with the largest area that were significantly greater in males compared to females and

292 juvenile males were 1-propanol, acetic acid, 2-butanol, guaiacol, anthranilic acid propyl ester,

293 (Z)-linalool oxide furanoid, phenol, 3-methylpyridine, propyl salicylate, 4-vinyl-2-

294 methoxyphenol, (E) or (Z)-linalool oxide (pyranoid), and 4-ethyl-2-methoxyphenol, respectively.

295 Linalool was approximately eight times higher in males (mean peak area) than females and

296 juvenile males but was only significantly different versus females. 
Figure 2 shows the overall odour fingerprint analysis as non-metric multidimensional 298 scaling (NMDS) plots for direct injection and headspace extracts, and for both the absolute and

299 relative percentage peak areas. In all cases, adult male profiles were distinct from those of adult

300 females and juvenile males, with the latter showing an overlapping pattern. Multivariate

301 statistical analysis of similarity of the relationship between grouping variable (adult and juvenile

302 males and adult females) and chemical composition of fur extract showed a significant effect of

303 group (Headspace ANOSIM on Bray-Curtis similarity matrix, $\mathrm{R}=0.4922, \mathrm{P} \leq 0.001$, Direct

304 Injection ANOSIM on Bray-Curtis similarity matrix, $\mathrm{R}=0.5911, \mathrm{P} \leq 0.001$ ).

306 Discussion

307 Odour fingerprint analysis of extracts of fur surrounding the shoulder gland of Sturnira

308 parvidens, using multivariate analysis, revealed clear, significant differences between adult

309 males versus both juvenile males and adult females. Many of the compounds identified included

310 terpenes and phenolics, together with alcohols and esters, and occurred exclusively or in elevated

311 quantities among adult (reproductive) males, compared with adult females and non-reproductive

312 sub-adult/juvenile males. This strongly suggests a specific role in male-female attraction for

313 these compounds, although a function in male-male competition and/or species recognition is

314 also possible. While non-reproductive responses have been attributed to pheromones (e.g.,

315 aggression and alarm signals), sexual stimulation and attraction are the most commonly

316 associated traits of pheromones (though the two responses can happen simultaneously to the

317 same substance for different individuals (Novotny, 2003)).

318 Among animals where vision is not a primary sensory modality, chemical cues have been

319 associated with species recognition. Many species of bat are highly gregarious, forming large, 
320 often multi-species colonies that are stable units (Kunz 1982), and chemical recognition is

321 known to assist in mother-pup recognition (De Fanis \& Jones 1996) and colony identification

322 (Bloss et al. 2002). Although relatively little is known about Sturnira social systems, they are not

323 known to roost in the large groups or colonies typical of many bats, but rather in small groups in

324 tree holes or other small cavities (Fenton et al., 2000). However, the distinctiveness of the

325 shoulder gland odour profiles that we have characterised for reproductively active adult males

326 suggests strongly that they are more likely to be involved in mating or mate choice. A small

327 number of other studies among bats have suggested a role for odour communication in individual

328 and social group recognition. Female big brown bats (Eptesicus fuscus) were able to use

329 chemical cues to distinguish roost mates and in a Y-maze experiment chose to preferentially

330 associate with the familiar cue (Bloss et al., 2002). In female Bechstein's bats, Myotis

331 bechsteinii, odour profiles from secretions of the facial interaural gland are individually specific

332 and differ between colonies, suggesting a function in individual and colony recognition (Safi \&

333 Kirth, 2003). A study of the distinctive odor of the fisherman bat (Noctilio leporinus), produced

334 by a secretion from glands in the sub-axillary region beneath the wings, identified 372 lipid

335 compounds (Brooke \& Decker, 1996). Differences in the chemical composition suggested that

336 secretions of males from the same roost were more similar to each other than to other males or

337 females. Furthermore, as secretions differed between the sexes, information on sexual identity

338 and reproductive condition could potentially be communicated. As with Sturnira parvidens,

339 another phyllostomid, the male greater spear-nosed bat, Phyllostomus hastatus, also possesses a

340 sexually dimorphic gland that produces an odoriferous secretion, but it is found on the chest

341 rather than the shoulder. A recent study by Adams et al., (2018) reports that secretions from male

342 harem holders, that defend and roost with groups of females, had significantly different chemical 
343 profiles from bachelor males found roosting in all male groups. Odour profiles also differed

344 significantly among individuals, suggesting that the chemical signal has the potential to

345 communicate both mating status and individual identity.

346 While the aforementioned provide good evidence for odour signals/pheromones playing

347 an important role in reproductive and social behaviour in bats, our study goes further in

348 identifying the chemical composition of the Sturnira parvidens odour signal. In the adult male

349 shoulder gland secretion, the components include terpenes and phenolics, together with alcohols

350 and esters. It is likely that these are derived from the frugivorous diet of Sturnira parvidens.

351 Bloss et al. (2002) identified 15 potential chemicals associated with female Eptesicus fuscus and,

352 of these, linalool was also found in our analysis of Sturnira parvidens, together with three

353 linalool derivatives, all of which were elevated in reproductive males. Linalool is a terpene

354 alcohol naturally produced by over 200 plant species, and there are many examples of it

355 functioning to attract insects to plants (e.g., hawkmoths; Raguso and Light, 1998), and is the

356 mate attractant pheromone in the bee Colletes cunicularius (Borg-Karlson et al., 2003),

357 suggesting a very broad biological action across plant and animal kingdoms.

358 Phenolics found in higher concentrations in the adult male secretions in our analysis

359 include vanillic acid (a natural phenol found, for example, in palm fruit), and guaiacol. The latter

360 is a component of the pheromone that causes locust swarming (Dillon et al., 2000) and produced

361 in the gut of desert locusts, Schistocerca gregaria, by the breakdown of plant material. Phenol

362 itself was also identified as a major component in our adult male samples, and interestingly is

363 also part of the temporal gland secretion of adult male elephants, which is thought to function to

364 attract females during muste, the periodic aggressive behavioural condition exhibited by bull 
365 elephants (Rasmussen \& Perrin, 1999). We also identified esters of ferulic acid, the latter being a

366 phenolic antioxidant found in the seeds of apples and oranges and the cell walls of many plants.

367 In addition to vanillic acid, we identified a number of other phenolic acids and propyl

368 esters derived from them (Supplementary Table 2). These included dihydroferulic,

369 hydroisoferulic, hydrosinapinic, veratric and anthranilic propyl esters and the hydroxypropyl

370 esters of dihydroferulic acid and anthranilic acid (Table 1). Interestingly, $\alpha, \beta$-dihydroferulic acid

371 propyl ester has been shown to exhibit strong antifungal action, perhaps suggesting a role beyond

372 just odour signalling for this compound (Beck et al., 2007). Significant quantities of 1-propanol

373 were found in the headspace analysis of the adult male compared to other alcohols. By contrast,

374 only small quantities of 1-propanol were found in the headspace of the juvenile male and the

375 female, suggesting that it and/or the propyl esters may play a role in pheromonal signalling in

376 this bat species. 1-Propanol may either be acting as a chemical signal in its own right, or

377 produced to form the aforementioned esters with the various phenolic acids. All the acids and

378 esters found in the adult male extract were at significantly higher levels than in the juvenile male

379 and the female. Additionally, anthranilic acid propyl ester was also identified in the headspace

380 analysis (Table 2) at significantly higher levels in the adult male than in the juvenile male and

381 the female. The hydroxypropyl esters of dihydroferulic acid and anthranilic are derived from

382 propylene glycol, which was also identified in significantly higher quantities in the headspace

383 analysis of the adult male, compared to the juvenile male and the female, suggesting that these

384 esters may also have pheromonal or semiochemical activity. Three of these esters (Table 2) have

385 not been previously reported and are unique to Sturnira parvidens.

386 Bacteria have been associated with the production of many chemical cues and it is

387 possible that these may also play a role in the synthesis of some of the compounds that we 
388 identified. In turn, these may contribute to individual and population-specific odour signatures in

389 Sturnira parvidens (if populations share local communities of bacteria in their shoulder glands).

390 In hyenas, bacterial species co-vary with odour profiles specific to populations, supporting such

391 a "fermentation hypothesis" of bacterial mediated chemical communication (Theis et al., 2013).

392 An investigation of bacteria associated with the epaulettes (shoulder glands) of the related bat

393 species Sturnira lilium and S. bogotensis revealed few common bacterial species between males

394 and females, offering the possibility for sex-specific odour production in the glands of males

395 (Gonzalez Quinonez et al., 2014).

\section{Conclusions}

397 In summary, many of the compounds we identified from our analysis were found exclusively or

398 in elevated quantities among adult (reproductive) males, compared with adult females and non-

399 reproductive males. Similar analyses of other Sturnira parvidens populations, and other Sturnira

400 species would be interesting, enabling a comparison of the variance in the composition of the

401 odour signal. Our results strongly suggests a specific role in male-female attraction in this

402 species, but further behavioural work is needed to confirm the functional significance of the

403 adult male shoulder gland secretions in Sturnira parvidens.

404

\section{Acknowledgements}

406 We thank the staff of the Lamanai Outpost Lodge, especially Mark Howells, Blanca Manzanilla,

407 Ruben Arvalo, and Eduardo Ruano for logistical support. We further thank the many field teams

408 on the Belize bat trip for contributing to data collection over many years.

409 


\section{References}

411 Adams DM, Li Y, Wilkinson GS. 2018. Male Scent Gland Signals Mating Status in Greater

412 Spear-Nosed Bats, Phyllostomus hastatus. Journal of Chemical Ecology 44:975 DOI:

413 org/10.1007/s10886-018-1003-8.

414 Anthony ELP. 1988. Age determination in bats. In: Kunz TH, Parsons S, eds. Ecological and

415 Behavioral Methods for the Study of Bats. Baltimore, Maryland: John Hopkins Press. 47-58

416 Beck JJ, Kim JH, Campbell BC, Chou S-C. 2007. Fungicidal activities of dihydroferulic acid

417 alkyl ester analogues. Journal of Natural Products 70:779-782 DOI: 10.1021/np0606345.

418 Bhatnagar KP, Meisami E. 1998. Vomeronasal organ in bats and primates: Extremes of

419 structural variability and its phylogenetic implications. Microscopy Research and Techniques

43:465-475 DOI: 10.1002/(SICI)1097-0029(19981215)43:6<465::AID-JEMT1>3.0.CO;2-1.

421

422

423

424

425

426

427

428

429

Bloss J, Acree TE, Bloss JM, Hood WR, Kunz TH. 2002. Potential use of chemical cues for colony-mate recognition in the big brown bat, Eptesicus fuscus. Journal of Chemical Ecology 28:819-834 DOI: 10.1023/A:101529692.

Borg-Karlson AK, Tengö J, Valterová I, Rikard Unelius C, Taghizadeh T, Tolasch T, Francke W. 2003. (S)-(+)-Linalool, a Mate Attractant Pheromone Component in the Bee Colletes cunicularius. Journal of Chemical Ecology 29:1 DOI: 10.1023/A:1021964210877.

Bouchard S. 2001. Sex discrimination and roostmate recognition by olfactory cues in the African bats, Mops condylurus and Chaerephon pumilus (Chiroptera: Molossidae). Journal of Zoology 254:109-117 DOI: 10.1017/S0952836901000607. 
430 Bowles JB, Heideman PD, Erickson KR. 1990. Observations on Six Species of Free-Tailed Bats

431 (Molossidae) from Yucatan, Mexico. The Southwestern Naturalist 35:151-157 DOI:

$43210.2307 / 3671536$.

433 Brooke AP, Decker DM. 1996. Lipid compounds in secretions of the fishing bat, Noctilio

434 leporinus (Chiroptera: Noctilionidae). Journal of Chemical Ecology 22:1411-1428 DOI:

$43510.1007 / \mathrm{BF} 02027721$.

436 Caspers B, Franke S, Voigt CC 2008. The wing-sac odour of male greater sac-winged bats

437 Saccopteryx bilineata (Emballonuridae) as a composite trait: seasonal and individual differences.

438 In: Hurst JL, Beynon RJ, Roberts SC, Wyatt TD eds. Chemical Signals in Vertebrates 11. New

439 York, NY: Springer. 151-160.

440 De Fanis E, Jones G. 1996. Allomaternal care and recognition between mothers and young in

441 Pipistrelle bats (Pipistrellus pipistrellus). Journal of Zoology 240:781-787 DOI: 10.1111/j.1469-

$442 \quad$ 7998.1996.tb05324.x.

443 Dehnhard M. 2011. Mammal semiochemicals: understanding pheromones and signature

444 mixtures for better zoo-animal husbandry and conservation. International Zoo Yearbook. 45:55-

44579 DOI: 10.1111/j.1748-1090.2010.00131.x.

446 Dillon RJ, Vennard CT, Charnley AK. 2000. Pheromones: Exploitation of gut bacteria in the

447 locust. Nature. 403:851 DOI: 10.1038/35002669.

448 Doty RL. 2010. The Great Pheromone Myth. Baltimore, MD: Johns Hopkins University Press.

449 Fenton MB, Vonhof MJ, Bouchard S, Gill SA, Johnston DS, Reid FA, Riskin DK, Standing KL, 
450 Taylor JR Wagner R. 2000. Roosts Used by Sturnira lilium (Chiroptera: Phyllostomidae) in

451 Belize. Biotropica 32:729-733 DOI: 10.1111/j.1744-7429.2000.tb00521.x.

452 Gannon MR, Willig MR, Jones Junior JK. 1989. Sturnira lilium. Mammalian Species 333:1-5

453 DOI: $10.2307 / 3504237$.

454 González-Quiñonez N, Fermin G, Muñoz-Romo M. 2014. Diversity of bacteria in the sexually

455 selected epaulettes of the little yellow-shouldered bat Sturnira lilium (Chiroptera:

456 Phyllostomidae) Interciencia 39:882-889

457 Goodwin GG, Greenhall AM. 1961. A review of the bats of Trinidad and Tobago: descriptions, 458 rabies infection, and ecology. Bulletin of the $A M N H, 122: 187-302$

459 Kunz TH. 1982. Ecology of bats. New York and London: Plenum Press

460 Novotny MV. 2003. Pheromones, binding proteins and receptor responses in rodents.

461 Biochemical Society Transactions 31:117-122 DOI: 10.1042/bst0310117.

462 Phillips CJ, Tandler B, Pinkstaff CA. 1987. Unique Salivary Glands in Two Genera of Tropical

463 Microchiropteran Bats: An Example of Evolutionary Convergence in Histology and

464 Histochemistry. Journal of Mammalogy 68:235-242 DOI: 10.2307/1381462.

465 R Core Team. 2015. R: a language and environment for statistical computing. Vienna: R

466 Foundation for Statistical Computing. Available at http:// www.R-project.org/ .

467 Racey PA 1988. Reproductive assessment in bats. In: Kunz TH, Parsons S, eds. Ecological and

468 Behavioral Methods for the Study of Bats. Baltimore, Maryland: John Hopkins Press. 31-45. 
469 Raguso RA, Light DM. 1998. Electroantennogram responses of male Sphinx perelegans

470 hawkmoths to floral and 'green-leaf volatiles'. Entomologia Experimentalis et Applicata 86:287-

471293 DOI: 0.1046/j.1570-7458.1998.00291.x.

472 Rasmussen LEL, Perrin TE. 1999. Physiological Correlates of Musth. Physiology \& Behavior $473 \quad 67: 539-49$

474 Safi K, Kirth G. 2003. Secretions of the interaural gland contain information about individuality

475 and colony membership in the Bechstein's bat. Animal Behaviour 65:363-369 DOI:

476 org/10.1006/anbe.2003.2067.

477 Schneeberger K, Voigt C., Müller C, Caspers BA. 2016. Multidimensionality of Chemical

478 Information in Male Greater Sac-Winged Bats (Saccopteryx bilineata). Frontiers in Ecology and

479 Evolution 4:281-7 DOI: 10.3389/fevo.2016.00083.

480 Schranz M, Lorber K, Klos K, Kerschbaumer J, Buettner A. 2017. Influence of the chemical

481 structure on the odor qualities and odor thresholds of guaiacol-derived odorants, part 1:

482 alkylated, alkenylated and methoxylated derivatives. Food Chemistry 232:808-819 DOI:

483 10.1016/j.foodchem.2017.04.070.

484 Scully WMR, Fenton MB, Saleuddin A SM. 2000. A histological examination of the holding

485 sacs and glandular scent organs of some bat species (Emballonuridae, Hipposideridae,

486 Phyllostomidae, Vespertilionidae, and Molossidae). Canadian Journal of Zoology 78:613-623

487 DOI: $10.1139 / \mathrm{z} 99-248$.

488 Sikes R, Gannon WL, And The Animal Care Use Committee Of The American Society Of

489 Mammalogists. 2016. Guidelines of the American Society of Mammalogists for the use of wild 
490 mammals in research and education. Journal of Mammalogy 97:663-688 DOI: 10.1644/10-

491 MAMM-F-355.1.

492 Simmons NB, Cirranello AL. 2019. Bat Species of the World: A taxonomic and geographic 493 database. Available at http://batnames.org (accessed March 2019)

494 Tandler B, Nagato T, Phillips CJ. 1997. Ultrastructure of the unusual accessory submandibular 495 gland in the fringe-lipped bat, Trachops cirrhosus. Anatomical Record 248:164-175 DOI: 10.1002/(SICI)1097-0185(199706)248:2<164::AID-AR3>3.0.CO;2-T.

497 Theis KR, Venkataraman A, Dycus JA, Koonter KD, Schmitt-Matzen EN, Wagner AP, 498 Holekamp KE, Schmidt TM. 2013. Symbiotic bacteria appear to mediate hyena social odors. 499 Proceedings of the National Academy of Sciences of the United States of America 110:1983250019837 DOI: 10.1073/pnas.1306477110.

501 Velazco PM, Patterson BD. 2013. Diversification of the yellow-shouldered bats, genus Sturnira

502 (Chiroptera, Phyllostomidae), in the New World tropics. Molecular Phylogenetics and Evolution 503 68:683-698 DOI: 10.1016/j.ympev.2013.04.016.

504 Velazco PM, Patterson BD 2014. Two new species of yellow-shouldered bats, genus Sturnira 505 Gray, 1842 (Chiroptera, Phyllostomidae) from Costa Rica, Panama and western Ecuador. 506 ZooKeys 402:43-66 DOI: 10.3897/zookeys.402.7228.

507 Voigt CC, von Helversen O. 1999. Storage and display of odour by male Saccopteryx bilineata 508 (Chiroptera, Emballonuridae). Behavioral Ecology and Sociobiology 47:29-40 DOI: $509 \quad 10.1007 / \mathrm{s} 002650050$. 
510 Voigt CC, Caspers B, Speck S. 2005. Bats, bacteria, and bat smell: sex-specific diversity of

511 microbes in a sexually selected scent organ. Journal of Mammalogy 86:745-749 DOI:

512 10.1644/1545-1542(2005)086[0745:BBABSS]2.0.CO;2.

513 Wible JR, Bhatnagar KP 1996. Chiropteran vomeronasal complex and the interfamilial

514 relationships of bats. Journal of Mammalian Evolution 3: 285-314

515 Wyatt TD. 2014. Pheromones and Animal Behavior: Chemical Signals and Signatures.

516 Cambridge: Cambridge University Press.

517 Wyatt TD 2017. Pheromones. Current Biology 27: R739-R743 DOI:

518 https://doi.org/10.1016/j.cub.2017.06.039.

519 Yohe LR, Abubakar R, Giordano C, Dumont E, Sears KE, Rossiter SJ, M. Davalos LM. 2017.

520 Trpc2 pseudogenization dynamics in bats reveal ancestral vomeronasal signalling, then pervasive

521 loss. Evolution 71:923-935 DOI: 10.1111/evo.13187.

522 Young JM, Massa HF, Hsu L, Trask BJ. 2010. Extreme variability among mammalian V1R gene

523 families. Genome Research 20:10-18 DOI: 10.1101/gr.098913.109. 


\section{Figure 1}

Sturnira parvidens adult male showing dark staining of fur surrounding the shoulder gland (Photo credit: Brock Fenton).

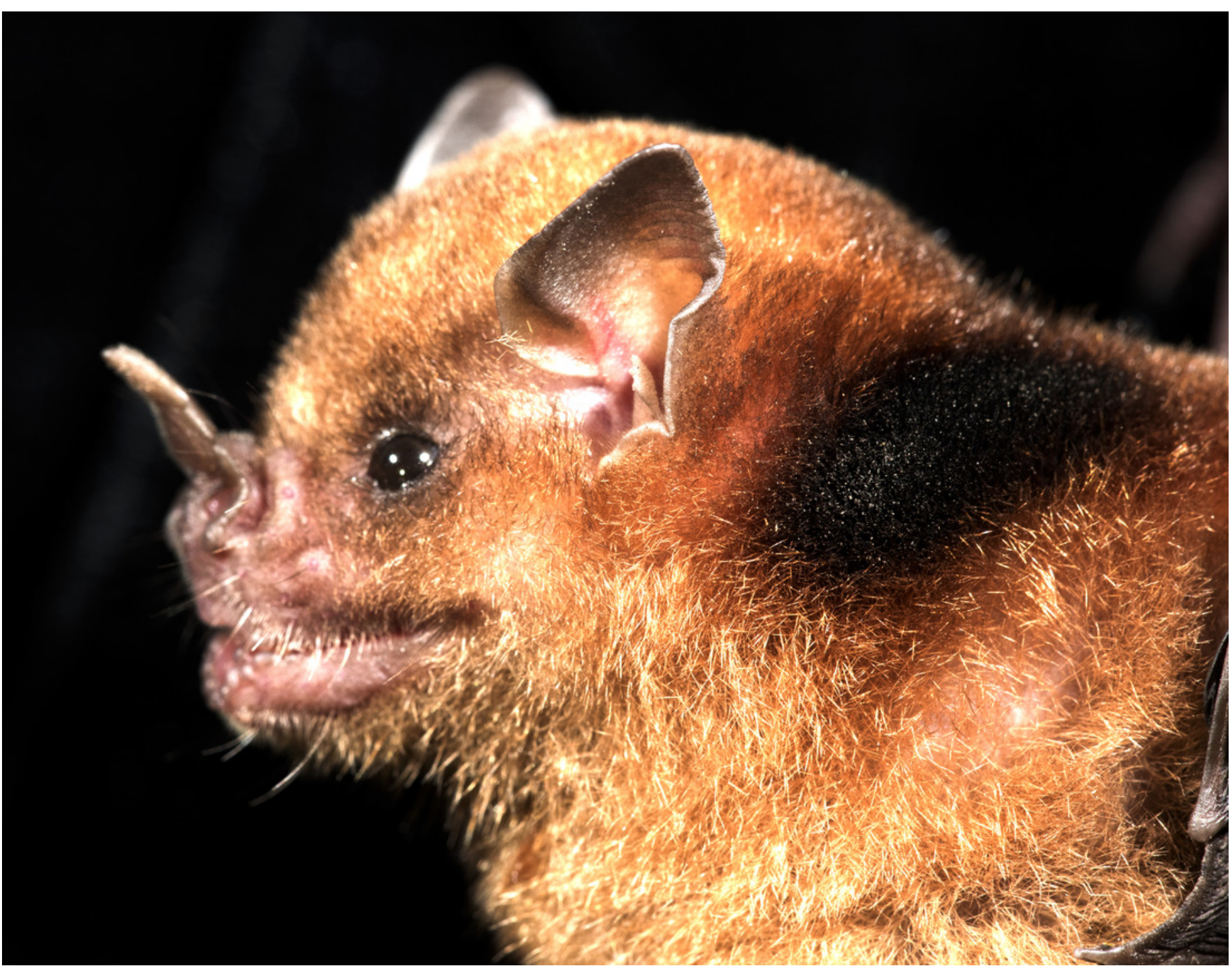




\section{Figure 2}

Non-metric multidimensional scaling (NMDS) plot.

Data represents the overall odour profiles of (a) and (c) direct injection, (b) and (d) headspace extracts from the shoulder gland secretions of adult males, adult females and juvenile (Juv) males. Profiles (a) and (b) are generated from the relative percentage peak area, while (c) and (d) are from absolute peak areas. Adult male profiles are distinct from those of females and juveniles, which show an overlapping pattern. Axes are dimensionless and have no units. 

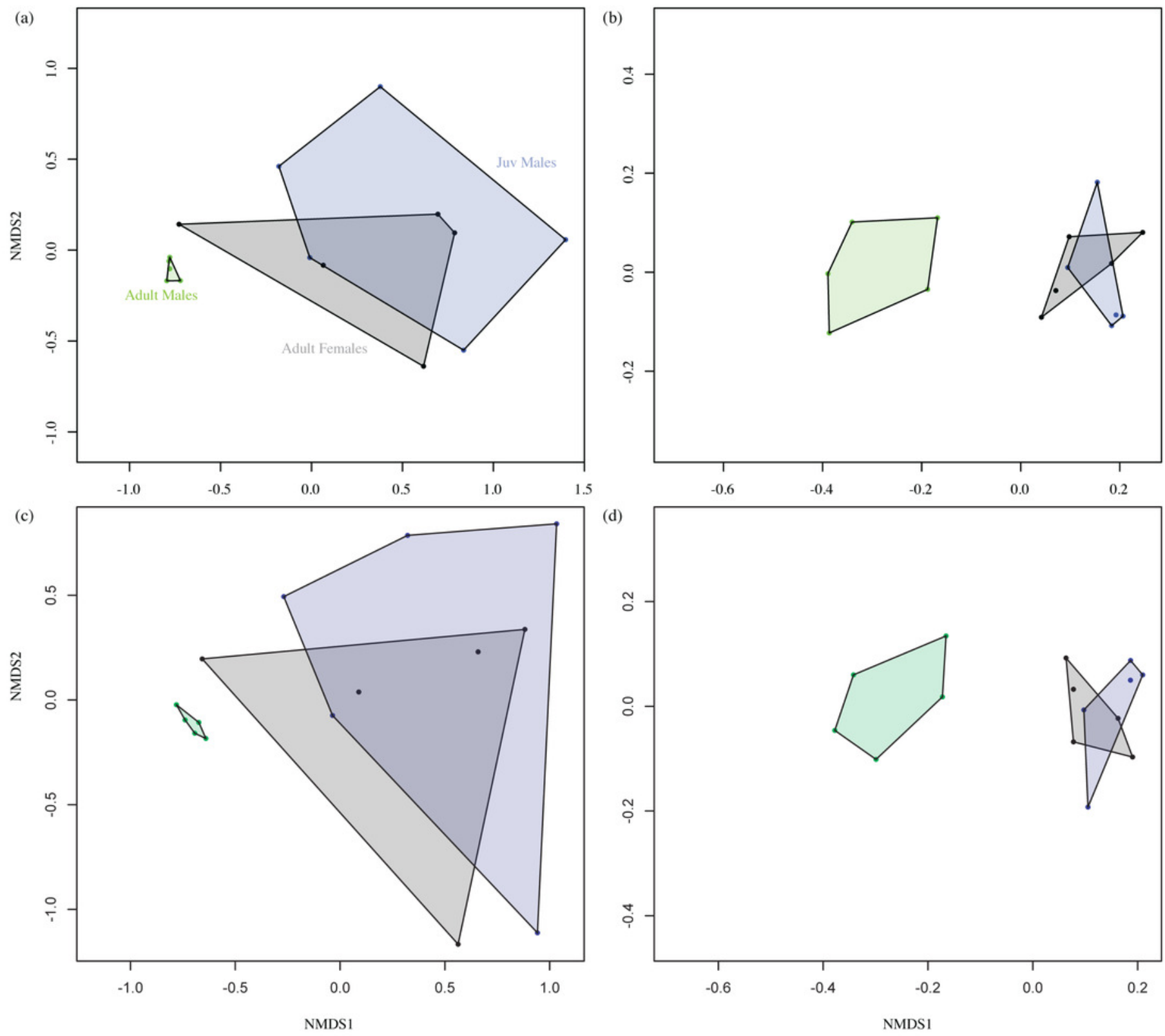


\section{Table $\mathbf{1}$ (on next page)}

Compounds in medium-chain triglyceride extracts of fur surrounding the shoulder gland of Sturnira parvidens.

Data are mean chromatographic peak areas (standard deviation in parentheses), together with relative peak areas expressed as a mean \% of the total across compounds (shown in italics). All identifications were confirmed with reference to standard compounds. LRI, linear retention index on a $15 \mathrm{~m} \times 0.25 \mathrm{~mm}(0.25 \mu \mathrm{m}$ film thickness) DB-5MS capillary column. $p=$ probability of a significant difference; Peak areas followed by the same letter are not significantly different $(p>0.05$ ), while peak numbers refer to Supplementary Figure 1. 


\begin{tabular}{|c|c|c|}
\hline $\begin{array}{l}\text { Peak } \\
\text { number }\end{array}$ & LRI & compound \\
\hline 1 & 1386 & anthranilic acid \\
\hline 2 & 1503 & anthranilic acid propyl ester \\
\hline 3 & 1552 & vanillic acid \\
\hline 4 & 1626 & 3,4-dimethoxybenzoic acid (veratric acid) \\
\hline 5 & 1666 & 4-(4-methoxyphenyl)butyric acid \\
\hline 6 & 1671 & vanillic acid propyl ester \\
\hline 7 & 1682 & anthranilic acid hydroxypropyl ester \\
\hline 8 & 1722 & $\begin{array}{l}\beta \text {-(4-hydroxy-3-methoxyphenyl)propionic acid }(\alpha, \beta- \\
\text { dihydroferulic acid) }\end{array}$ \\
\hline 9 & 1741 & $\begin{array}{l}\beta \text {-(3-hydroxy-4-methoxyphenyl)propionic acid } \\
\text { (hydroisoferulic acid) }\end{array}$ \\
\hline 10 & 1744 & veratric acid propyl ester \\
\hline 11 & 1764 & 3-(3,4-dimethoxyphenyl)propionic acid \\
\hline 12 & 1828 & $\alpha, \beta$-dihydroferulic acid, propyl ester \\
\hline 13 & 1852 & hydroisoferulic acid, propyl ester \\
\hline 14 & 1984 & $\alpha, \beta$-dihydroferulic acid, hydroxypropyl ester \\
\hline 15 & 2055 & $\begin{array}{l}\text { 3-(3,5-dimethoxy-4-hydroxyphenyl)propionic acid propyl } \\
\text { ester (hydrosinapinic acid propyl ester) }\end{array}$ \\
\hline
\end{tabular}

gas chromatographic

peak areas $\left(\times 10^{-6}\right)$

relative peak areas

$(\%)$

\begin{tabular}{|c|c|c|c|}
\hline adult male & juvenile male & adult female & \\
\hline $3.95(1.78)$ & $0.161(0.212)$ & $0.153(0.262)$ & NS \\
\hline $4.92(3.73)$ & $10.92(12.93)$ & $5.09(7.59)$ & NS \\
\hline $14.7(11.4) \mathbf{b}$ & $0.214(0.234) \mathbf{a}$ & $0.186(0.126) \mathbf{a}$ & $<0.05$ \\
\hline $11.86(3.28)$ & $15.59(11.21)$ & $18.69(7.98)$ & NS \\
\hline $0.429(0.061)$ & - & - & $<0.001$ \\
\hline $0.72(0.70)$ & - & - & $<0.0001$ \\
\hline $1.46(0.945)$ & - & - & $<0.001$ \\
\hline $1.43(0.67)$ & - & - & $<0.0001$ \\
\hline $12.6(16.8) \mathbf{b}$ & $0.0107(0.0239) \mathbf{a}$ & $0.0335(0.0749) \mathbf{a}$ & $<0.001$ \\
\hline $6.78(3.07) \boldsymbol{b}$ & $0.67(1.50) \boldsymbol{a}$ & $0.94(2.10) \boldsymbol{a}$ & $<0.01$ \\
\hline $5.15(6.42)$ & $0.0058(0.0129)$ & $0.0190(0.0426)$ & NS \\
\hline $2.18(2.11)$ & $0.82(1.83)$ & $0.53(1.19)$ & NS \\
\hline $3.30(2.54)$ & $0.0570(0.109)$ & $0.054(0.0741)$ & NS \\
\hline $2.48(0.57)$ & $2.38(4.19)$ & $2.14(3.09)$ & NS \\
\hline $3.73(2.77) \mathbf{a}$ & $0.298(0.262) \mathbf{a b}$ & $0.172(0.174) \mathbf{b}$ & $<0.05$ \\
\hline $3.44(1.51)$ & $34.56(33.65)$ & $2.14(3.09)$ & NS \\
\hline $0.802(0.648)$ & $0.0147(0.0223)$ & $0.0049(0.0108)$ & NS \\
\hline $0.72(0.41)$ & $0.81(1.37)$ & $1.26(2.81)$ & NS \\
\hline $0.401(0.233)$ & $0.0063(0.0140)$ & $0.0155(0.0346)$ & NS \\
\hline $0.42(0.24)$ & $0.39(0.88)$ & $0.43(0.97)$ & NS \\
\hline $0.711(0.621)$ & - & - & $<0.001$ \\
\hline $0.54(0.16)$ & - & - & $<0.0001$ \\
\hline $96.3(95.7) \mathbf{b}$ & $0.427(0.416) \mathbf{a}$ & $0.688(0.712) \mathbf{a}$ & $<0.001$ \\
\hline $60.21(16.39) \boldsymbol{a}$ & $33.38(26.14) \boldsymbol{b}$ & $49.43(11.71) \boldsymbol{a b}$ & $<0.06$ \\
\hline $3.16(3.19) \mathbf{b}$ & - & $0.0233(0.0412) \mathbf{a}$ & $<0.01$ \\
\hline $2.03(0.74)$ & - & $2.35(3.94)$ & $N S$ \\
\hline $2.62(2.47) \mathbf{b}$ & $0.0121(0.0270) \mathbf{a}$ & $0.0297(0.0425) \mathbf{a}$ & $<0.05$ \\
\hline $1.64(0.43)$ & $0.47(1.05)$ & $1.11(1.53)$ & NS \\
\hline $1.14(1.48) \mathbf{b}$ & - & $0.0083(0.0185) \mathbf{a}$ & $<0.05$ \\
\hline $0.63(0.37) \boldsymbol{b}$ & - & $0.23(0.52) \boldsymbol{a}$ & $<0.05$ \\
\hline
\end{tabular}




\section{PeerJ}




\section{Table 2 (on next page)}

Headspace compounds in medium-chain triglyceride extracts of fur surrounding the shoulder gland of Sturnira parvidens, obtained using solid-phase microextraction.

Data are mean chromatographic peak areas (standard deviation in parentheses), together with relative peak areas expressed as a mean \% of the total across compounds (shown in italics). $p=$ probability of a significant difference; Peak areas followed by the same letter are not significantly different $(p>0.05)$ ), while peak numbers refer to Supplementary Figure 2. 


\begin{tabular}{|c|c|c|c|c|c|c|c|}
\hline \multirow{2}{*}{$\begin{array}{l}\text { Peak } \\
\text { number }\end{array}$} & \multirow{2}{*}{$\begin{array}{l}\text { linear } \\
\text { retention } \\
\text { index } \\
(\mathrm{LRI})^{\mathrm{a}}\end{array}$} & \multirow[b]{2}{*}{ compound } & \multirow{2}{*}{$\begin{array}{l}\text { confirmation } \\
\text { of identity }\end{array}$} & \multicolumn{3}{|c|}{ gas chromatographic peak areas $\left(\times 10^{-6}\right)$} & \multirow[b]{2}{*}{$p$} \\
\hline & & & & adult male & juvenile male & adult female & \\
\hline \multirow[t]{2}{*}{1} & 904 & ethyl acetate & Std & $93.9(17.9) \mathbf{a}$ & $120(10.8) \mathbf{b}$ & $126(9.31) \mathbf{b}$ & 0.006 \\
\hline & & & & $6.46(2.27) \boldsymbol{a}$ & $17.86(2.83) \boldsymbol{b}$ & $17.89(1.85) \boldsymbol{b}$ & $<0.01$ \\
\hline \multirow[t]{2}{*}{2} & 912 & isopropyl acetate & Std & $41.4(9.89) \mathbf{a}$ & $51.2(7.70) \mathbf{a b}$ & $55.3(4.87) \mathbf{b}$ & 0.041 \\
\hline & & & & $2.85(1.08) \boldsymbol{a}$ & $7.64(1.39) b$ & $7.85(0.60) \boldsymbol{b}$ & $<0.05$ \\
\hline \multirow[t]{2}{*}{3} & 916 & 2-butanone & Std & $52.6(18.6)$ & $61.6(10.7)$ & $67.9(9.64)$ & NS \\
\hline & & & & $3.67(1.81) \boldsymbol{a}$ & $9.19(1.92) \boldsymbol{b}$ & $9.60(0.87) \boldsymbol{b}$ & $<0.05$ \\
\hline \multirow{2}{*}{4} & 939 & isopropyl alcohol & Std & $76.4(23.0)$ & $90.7(8.95)$ & $96.8(6.14)$ & NS \\
\hline & & & & $5.52(3.55) \boldsymbol{a}$ & $13.72(3.35) \boldsymbol{b}$ & $13.93(2.50) \boldsymbol{a}$ & $<0.05$ \\
\hline \multirow[t]{2}{*}{5} & 947 & ethanol & Std & $115(47.8)$ & $162(43.5)$ & $154(22.6)$ & NS \\
\hline & & & & $7.40(1.95) \boldsymbol{a}$ & $24.56(8.64) \boldsymbol{b}$ & $22.14(5.13) \boldsymbol{b}$ & $<0.05$ \\
\hline \multirow{2}{*}{6} & 972 & ethyl propanoate & Std & $9.78(2.36)$ & $9.91(1.95)$ & $10.7(2.47)$ & NS \\
\hline & & & & $0.68(0.28) \boldsymbol{a}$ & $1.47(0.30) \boldsymbol{b}$ & $1.57(0.54) \boldsymbol{b}$ & $<0.05$ \\
\hline \multirow[t]{2}{*}{7} & 1030 & alpha-pinene & Std & $8.81(0.994)$ & $12.6(8.36)$ & $12.8(12.2)$ & NS \\
\hline & & & & $0.60(0.17)$ & $1.96(1.57)$ & $1.65(1.31)$ & $N S$ \\
\hline \multirow[t]{2}{*}{8} & 1038 & 2-butanol & Std & $17.0(4.15) \mathbf{b}$ & $9.02(1.15) \mathbf{a}$ & $7.06(3.50) \mathbf{a}$ & 0.001 \\
\hline & & & & $1.13(0.26)$ & $1.34(0.22)$ & $0.98(0.49)$ & $N S$ \\
\hline \multirow[t]{2}{*}{9} & 1052 & 1-propanol & Std & $674(114) \mathbf{b}$ & $44.4(73.7) \mathbf{a}$ & $50.0(65.4) \mathbf{a}$ & $<0.0001$ \\
\hline & & & & $44.58(8.12) \boldsymbol{b}$ & $5.90(9.32) \boldsymbol{a}$ & $6.23(7.09) \boldsymbol{a}$ & $<0.01$ \\
\hline \multirow[t]{2}{*}{10} & 1096 & $\mathrm{~N}, \mathrm{~N}$-dimethylhydroxylamine & MS & $10.3(9.53)$ & $4.40(5.63)$ & $11.8(10.9)$ & NS \\
\hline & & & & $4.79(9.17)$ & $0.52(0.65)$ & $1.43(1.15)$ & $N S$ \\
\hline \multirow[t]{2}{*}{11} & 1132 & 2-pentanol & Std & $2.28(1.35) \mathbf{b}$ & $0.776(0.078) \mathbf{a}$ & $0.956(0.156) \mathbf{a b}$ & 0.021 \\
\hline & & & & $0.14(0.04)$ & $0.12(0.01)$ & $0.14(0.02)$ & $N S$ \\
\hline \multirow[t]{2}{*}{12} & 1138 & 3-methylthiophene & Std & $2.66(2.25)$ & $5.83(10.9)$ & $1.32(1.45)$ & NS \\
\hline & & & & $0.15(0.11)$ & $0.73(1.34)$ & $0.98(0.49)$ & $N S$ \\
\hline \multirow[t]{2}{*}{13} & 1140 & 1-methoxy-2-propanol & Std & $7.64(4.21)$ & $8.36(5.27)$ & $10.6(3.71)$ & NS \\
\hline & & & & $0.47(0.16) \boldsymbol{a}$ & $1.25(0.85) \boldsymbol{a b}$ & $1.49(0.52) \boldsymbol{b}$ & $<0.05$ \\
\hline \multirow[t]{2}{*}{14} & 1156 & 1-butanol & Std & $9.55(6.42)$ & $4.66(0.587)$ & $4.32(1.03)$ & NS \\
\hline & & & & $0.58(0.22) \boldsymbol{a}$ & $0.69(0.10) \boldsymbol{b}$ & $0.61(0.11) \boldsymbol{a b}$ & $<0.05$ \\
\hline \multirow{2}{*}{15} & 1212 & limonene & Std & $5.19(2.00)$ & $3.85(3.25)$ & $3.68(1.44)$ & NS \\
\hline & & & & $0.33(0.14)$ & $0.54(0.37)$ & $0.53(0.22)$ & $N S$ \\
\hline \multirow[t]{2}{*}{16} & 1262 & 3-methyl-3-buten-1-ol & Std & $3.95(3.15)$ & $3.28(3.79)$ & $11.7(15.7)$ & NS \\
\hline & & & & $0.25(0.14) \boldsymbol{a}$ & $0.43(0.47) \boldsymbol{a b}$ & $1.46(1.69) \boldsymbol{b}$ & $<0.05$ \\
\hline
\end{tabular}




\begin{tabular}{|c|c|c|}
\hline 17 & 1313 & 3-methylpyridine \\
\hline 18 & 1404 & methyl octanoate \\
\hline 19 & 1448 & ethyl octanoate \\
\hline 20 & 1457 & (E)-linalool oxide furanoid \\
\hline 21 & 1474 & acetic acid \\
\hline 22 & 1485 & (Z)-linalool oxide furanoid \\
\hline 23 & 1533 & propyl octanoate \\
\hline 24 & 1551 & benzaldehyde \\
\hline 25 & 1558 & linalool \\
\hline 26 & 1560 & propanoic acid \\
\hline 27 & 1620 & propylene glycol \\
\hline 28 & 1648 & butyric acid \\
\hline 29 & 1663 & acrylic acid \\
\hline 30 & 1757 & pentanoic acid \\
\hline 31 & 1777 & $\begin{array}{l}(E) \text { - or }(Z) \text {-linalool oxide } \\
\text { (pyranoid) }\end{array}$ \\
\hline 32 & 1847 & 3,4-dimethylbenzaldehyde \\
\hline 33 & 1864 & hexanoic acid \\
\hline 34 & 1886 & guaiacol \\
\hline 35 & 1899 & benzyl alcohol \\
\hline 36 & 1925 & propyl salicylate \\
\hline
\end{tabular}

$\begin{array}{cc}\text { Std } & 1.17(0.619) \mathbf{b} \\ & 0.08(0.04) \boldsymbol{a} \\ \mathrm{Std} & 5.51(5.69) \\ & 0.29(0.24) \\ \mathrm{Std} & 3.04(2.70) \\ & 0.17(0.11) \\ \mathrm{Std} & 0.974(1.08) \\ & 0.05(0.05) \boldsymbol{b} \\ \mathrm{Std} & 38.9(14.7) \mathbf{b} \\ & 2.68(1.41) \\ \mathrm{Std} & 3.98(3.92) \mathbf{b} \\ & 0.24(0.23) \boldsymbol{b} \\ \mathrm{Std} & 21.6(31.2) \\ & 1.07(1.45) \boldsymbol{b} \\ \mathrm{Std} & 2.32(1.27) \\ & 0.16(0.11) \boldsymbol{a} \\ \mathrm{Std} & 0.855(0.753) \mathbf{b} \\ & 0.05(0.04) \\ \mathrm{Std} & 2.83(0.843) \mathbf{b} \\ & 0.19(0.06) \\ \mathrm{Std} & 41.4(39.3) \mathbf{b} \\ & 2.68(2.74) \boldsymbol{b} \\ \mathrm{Std} & 3.62(2.13) \\ & 0.24(0.15) \\ \mathrm{Std} & 9.29(3.74) \\ & 0.59(0.12) \boldsymbol{a} \boldsymbol{b} \\ \mathrm{Std} & 1.44(1.27) \\ & 0.10(0.11) \\ \mathrm{Std} & 0.926(0.808) \mathbf{b} \\ & 0.05(0.04) \boldsymbol{b} \\ \mathrm{Std} & 1.85(0.362) \\ & 0.13(0.04) \boldsymbol{a} \\ \mathrm{Std} & 4.04(1.43) \mathbf{b} \\ & 0.26(0.07) \\ \mathrm{Std} & 8.19(7.91) \mathbf{b} \\ & 0.50(0.54) \boldsymbol{b} \\ \mathrm{Std} & 5.85(8.05) \\ & 0.44(0.67) \boldsymbol{b} \\ \mathrm{Std} & 1.02(0.707) \mathbf{b} \\ & 0.07(0.06) \boldsymbol{b} \\ & \\ & \\ & \end{array}$

$$
\begin{gathered}
0.248(0.156) \mathbf{a} \\
0.03(0.02) \boldsymbol{b} \\
6.18(10.4) \\
0.79(1.26) \\
3.58(4.77) \\
0.47(0.57) \\
0.011(0.024) \\
<0.00(0.00) \mathbf{a} \\
15.1(7.80) \mathbf{a} \\
2.15(0.77) \\
0.043(0.043) \mathbf{a} \\
0.01(0.01) \boldsymbol{a} \\
0.360(0.328) \\
0.05(0.04) \boldsymbol{a} \\
1.45(0.167) \\
0.21(0.02) \boldsymbol{b} \\
0.127(0.029) \mathbf{a b} \\
0.02(0.01) \\
1.61(0.753) \mathbf{a} \\
0.23(0.07) \\
2.46(0.598) \mathbf{a} \\
0.36(0.06) \boldsymbol{a} \\
1.51(0.967) \\
0.21(0.11) \\
2.78(3.58) \\
0.37(0.42) \boldsymbol{a} \\
0.527(0.293) \\
0.07(0.03) \\
0.006(0.013) \mathbf{a} \\
<0.00(0.00) \boldsymbol{a} \\
2.16(0.506) \\
0.32(0.06) \boldsymbol{b} \\
1.68(1.13) \mathbf{a} \\
0.23(0.12) \\
0.075(0.029) \mathbf{a} \\
0.01(0.00) \boldsymbol{a} \\
0.210(0.045) \\
0.03(0.00) \boldsymbol{a} \\
0.024(0.018) \mathbf{a} \\
<0.00(0.00) \boldsymbol{a} \\
\end{gathered}
$$

0.005

$5.53(5.17) \quad \mathrm{NS}$

$0.79(1.26) \quad N S$

$4.84(4.56)-\mathrm{NS}$

$0.69(0.65) \quad N S$

$0.042(0.040) \quad 0.05$

$0.01(0.01) \boldsymbol{a} \quad<0.01$

$17.9(3.65) \mathbf{a} \quad 0.005$

$2.56(0.57) \quad N S$

$0.080(0.079) \mathbf{a} \quad 0.026$

$0.01(0.01) a<<0.01$

$0.458(0.400) \quad$ NS

$0.06(0.06) \boldsymbol{a} \quad<0.01$

$1.54(0.187) \quad \mathrm{NS}$

$0.22(0.04) \boldsymbol{b}<0.01$

$0.104(0.062) \mathbf{a} \quad 0.029$

$0.02(0.01) \quad N S$

. $852(0.318) \mathbf{a b} \quad 0.034$

$4.38(1.24) \mathbf{a b} \quad 0.032$

$0.63(0.21) \boldsymbol{a} \quad<0.01$

$2.31(1.32) \quad \mathrm{NS}$

$0.33(0.19)$

$7.40(4.88) \quad \mathrm{NS}$

$1.01(0.57) \boldsymbol{b} \quad<0.01$

$0.722(0.263) \quad$ NS

$0.10(0.04) \quad N S$

$0.025(0.035) \mathbf{a} \quad 0.013$

$<0.00(0.00) \boldsymbol{a} \quad<0.01$

$2.01(0.421) \quad \mathrm{NS}$

$0.29(0.07) \boldsymbol{b} \quad<0.01$

$1.80(0.880) \mathbf{a}$

$0.26(0.13) \quad N S$

$0.116(0.063) \mathbf{a} \quad 0.023$

$0.02(0.01) \boldsymbol{a}<0.01$

$0.704(0.502) \quad$ NS

$0.10(0.07) a b$

$0.027(0.015) \mathbf{a} \quad 0.003$

$<0.01$ 


\begin{tabular}{|c|c|c|c|c|c|c|c|}
\hline 37 & 2031 & phenol & Std & $\begin{array}{c}1.48(0.382) \mathbf{b} \\
0.01(0.03) \boldsymbol{a b}\end{array}$ & $\begin{array}{c}0.326(0.089) \mathbf{a} \\
0.05(0.01) \boldsymbol{a}\end{array}$ & $\begin{array}{c}0.772(0.252) \mathbf{a} \\
0.11(0.04) \boldsymbol{b}\end{array}$ & $\begin{array}{l}0.0001 \\
<0.01\end{array}$ \\
\hline 38 & 2056 & 5-ethyl-2-methoxyphenol & MS + LRI & $\begin{array}{c}0.742(0.563) \mathbf{b} \\
0.04(0.02) \boldsymbol{b}\end{array}$ & $\begin{array}{l}0.032(0.023) \mathbf{a} \\
<0.00(0.00) \boldsymbol{a}\end{array}$ & $\begin{array}{l}0.025(0.006) \mathbf{a} \\
<0.00(0.00) \boldsymbol{a}\end{array}$ & $\begin{array}{l}0.006 \\
<0.01\end{array}$ \\
\hline 39 & 2061 & 4-ethyl-2-methoxyphenol & Std & $\begin{array}{c}0.551(0.639) \\
0.03(0.03) \boldsymbol{b}\end{array}$ & $\begin{array}{l}0.019(0.011) \\
<0.00(0.00) a\end{array}$ & $\begin{array}{l}0.023(0.009) \\
<0.00(0.00) a\end{array}$ & $\begin{array}{c}\mathrm{NS} \\
<0.01\end{array}$ \\
\hline 40 & 2076 & octanoic acid* & Std & $\begin{array}{c}200(302) \\
9.78(14.14)\end{array}$ & $\begin{array}{l}49.8(81.0) \\
6.43(9.76)\end{array}$ & $\begin{array}{l}32.9(28.7) \\
4.71(4.17)\end{array}$ & $\begin{array}{l}\mathrm{NS} \\
N S\end{array}$ \\
\hline 41 & 2197 & 4-vinyl-2-methoxyphenol & Std & $\begin{array}{c}1.01(0.635) \mathbf{b} \\
0.06(0.03) \boldsymbol{b}\end{array}$ & $\begin{array}{c}0.032(0.025) \mathbf{a} \\
<0.00(0.00) \boldsymbol{a}\end{array}$ & $\begin{array}{c}0.038(0.022) \mathbf{a} \\
0.01(0.00) \boldsymbol{a}\end{array}$ & $\begin{array}{l}0.002 \\
<0.01\end{array}$ \\
\hline 42 & $>2200$ & anthranilic acid propyl ester & Std & $\begin{array}{l}5.71(4.55) \mathbf{b} \\
0.35(0.30) \boldsymbol{b}\end{array}$ & $\begin{array}{c}0.150(0.054) \mathbf{a} \\
0.02(0.01) \boldsymbol{a}\end{array}$ & $\begin{array}{c}0.222(0.124) \mathbf{a} \\
0.03(0.02) \boldsymbol{a}\end{array}$ & $\begin{array}{l}0.008 \\
<0.01\end{array}$ \\
\hline
\end{tabular}

3 a Linear retention index on a $30 \mathrm{~m} \times 0.25 \mathrm{~mm}(0.5 \mu \mathrm{m}$ film thickness $)$ Stabilwax DA capillary column

4 b Std: standard compound run under the same conditions; MS + LRI: mass spectrum and linear retention index similar to literature spectrum (Schranz et al., 5 2017); MS: mass spectrum similar to literature spectrum (NIST11.L for Chemstation)

6 *octanoic acid is also contributed by breakdown of the MCT solvent. 